- Interventions aimed at reducing the stress experienced by dental practitioners and other members of the dental team should be sufficiently flexible to address the complex nature of dental practice.

- Complex interventions necessitate evaluations which address a broad range of outcomes, including the experience of stress, coping mechanisms, behavioural change and exposure to stressors.

\title{
How to reduce the stress of general dental practice: The need for research into the effectiveness of multifaceted interventions
}

\author{
J. T. Newton, ${ }^{1}$ C. D. Allen, ${ }^{2}$ J. Coates, ${ }^{3}$ A. Turner ${ }^{4}$ and J. Prior ${ }^{5}$
}

While the practice of dentistry has been demonstrated to be significantly stressful, there have been few published studies describing interventions to reduce the stress of dental practitioners. This article describes research into the prevention and alleviation of stress amongst a variety of healthcare professionals, including dental practitioners, and describes the findings from a small scale study of an intervention aimed at general dental practitioners who reported high levels of work related stress. It is argued that to be effective, interventions should be tailored to the individual needs of the practitioner, within a structured intervention framework. Further research into the effectiveness and cost-effectiveness of stress management for dental practitioners is required.

The research described here was approved by the Local Research Ethics Committee of West Kent Health Authority.

\section{STRESS IN DENTAL PRACTICE}

There is a considerable body of evidence that suggests that dental practitioners experience high levels of stress within their working lives (see Gibbons and Newton ${ }^{1}$ for a summary). These high levels of stress are associated with significant distress, including a number of signs and symptoms. Stress has been related to medical problems, to feelings of low self-esteem, depression and anxiety, and to feelings of hopelessness. ${ }^{2}$ General dental practitioners have a higher risk of suicide than the gen-

\footnotetext{
1*Professor of Psychology as Applied to Dentistry, GKT Dental Institute; ${ }^{2}$ Consultant in Dental Public Health, West Kent Health Authority; ${ }^{3}$ Customer Services Manager, West Kent Health Authority; ${ }^{4}$ Head of Conciliation and Mediation service, West Kent Health Authority; ${ }^{5}$ Clinical Psychologist, West Kent Health Authority ${ }^{*}$ Correspondence to: Professor J. T. Newton, Oral Health Services Research \& Dental Public Health, GKT Dental Institute, Caldecot Road, London SE5 9RW Email:tim.newton@kcl.ac.uk
}

\section{Refereed Paper}

Accepted 27 September 2005

doi: 10.1038/sj.bdj.4813463

๑ British Dental Journal 2006; 200: 437-440 eral population. Stress related disorders are a common cause of early retirement among the dental profession. ${ }^{3}$ Furthermore high levels of work-related stress have been shown to be related to job dissatisfaction and poor working relationships. ${ }^{4}$

The sources of stress for dentists are varied, including financial worries, business problems, difficulties with patients and feelings of time urgency and pressure, ${ }^{4-6}$ but may in part be related to the dentists' career expectations. ${ }^{7}$ There is limited evidence that the degree of stress experienced by dental practitioners may vary according to the type of dentistry they practice - whether specialist or general dental practice, and between specialties - and according to the framework of remuneration within which they work. ${ }^{6,8}$ Much of this research has been carried out as cross-sectional surveys of groups of dental practitioners.

\section{Intervening to reduce stress}

There have been a number of intervention studies published which have sought to reduce the impact of stress in groups facing particular health and social pressures. For example: asthma $;{ }^{9}$ hypertension and heart disease; ${ }^{10,11}$ brain injury; ${ }^{12}$ caring for an older relative with dementia. ${ }^{13,14}$ Most have demonstrated reductions in the distress experienced by individuals facing such chronic stressors. In addition there have been numerous recommendations made concerning stress intervention in the work place. ${ }^{15-17}$ These generally recommend that stress reduction should not be viewed solely as a problem of the individual and that managers have a responsibility to seek to provide a stress free work environment for all employees. Intervention studies aimed at reducing stress in the work place have generally shown that debriefing individuals following major stressors is effective, as is the provision of support to individuals experiencing high levels of stress. ${ }^{18-20}$ It has been suggested that intervention programmes aimed at ameliorating the harmful effects of stress should be supplemented by primary prevention with the goal of improving the working conditions of dental practitioners. ${ }^{21}$ However at least one systematic review of the role of primary prevention in stress management in the workplace has suggested that such an approach is less beneficial than symptomatic management. ${ }^{22}$ There is currently no research describing the impact of primary prevention on the stress levels of dental practitioners. 


Table 1 Broad areas covered in intervention
sessions with consultants
Areas addressed in sessions with consultants
Personal issues: High expectations of self, isolation
(personal and professionall), loss of confidence, low
self-esteem, unresolved prior traumatic experiences
Home/work balance: Particularly for female dentists
The work at the practice: Long hours, paperwork,
bureaucracy, patient complaints, the piecework
system of payment
Interpersonal stress in the practice: Assertiveness to
other staff, managing staff
Concern for other dentists in the NHS: Mention of
stress as common amongst dentists in the NHS

To date there have been few published studies of workplace interventions for dental practitioners. Gorter, Eijkman and Hoogstraten $^{23}$ identified 191 dentists who were experiencing burn-out (as indicated by high scores on the Maslach Burnout Inventory). Of these, 19 agreed to participate in a six month intervention comprising cognitive and behavioural interventions. Participants in the psychological intervention showed decreased burn-out scores at the end of the intervention. There was also evidence that the control participants, who did not receive any intervention, could be differentiated into two groups - those that spontaneously took some action to alleviate their burn-out, and those that did not act to alleviate their stress. Those that spontaneously acted to reduce their burn-out showed decreased burn-out at the six month follow up. In a published one year follow up of the participants, the researchers found that participants in the intervention demonstrated relapse in their burn-out scores, however those dental practitioners who had spontaneously acted to reduce their stress showed sustained improvements. ${ }^{24}$ The implication of these studies is that interventions to reduce the stress and burn-out of dental practitioners should focus on assisting practitioners to create change which they can maintain, simple feedback on the level of stress they are experiencing may be sufficient to promote change in well motivated practitioners.

\section{The Kent Dental Practitioners Support Service}

Within the Kent area the new Dental Practitioners Support Service (DPSS) has been developed with the specific goal of helping dentists who are facing high levels of stress. The service aims to identify the problems faced by individual dentists and to direct the dentist to appropriate sources of help, and consists of an initial assessment with a trained counsellor. On the basis of the issues identified in the initial assessment the counsellor may refer the

\begin{tabular}{|c|c|c|}
\hline \multirow[t]{2}{*}{ Measure } & \multirow{2}{*}{$\begin{array}{l}\text { Time } 1 \\
\text { (Pre- } \\
\text { intervention) } \\
\text { Mean (SD) }\end{array}$} & $\begin{array}{l}\text { Time } 2 \\
\text { (Post- } \\
\text { ) intervention }\end{array}$ \\
\hline & & Mean (SD) \\
\hline $\begin{array}{l}\text { General Health } \\
\text { Questionnaire } \\
\text { (General distress) }\end{array}$ & $14.8(5.4)$ & 9.38 (3.29) \\
\hline \multicolumn{3}{|c|}{ Clinical Outcomes in Research \& Evaluation } \\
\hline CORE - F & $0.93(0.34)$ & $0.96(0.45)$ \\
\hline CORE - P & $1.44(0.68)$ & $0.89(0.68)$ \\
\hline CORE - W & $1.16(0.80)$ & $0.75(0.64)$ \\
\hline CORE - R & $0.15(0.24)$ & $0.06(0.12)$ \\
\hline CORE - TOTAL & $1.00(0.45)$ & $0.79(0.47)$ \\
\hline \multicolumn{3}{|c|}{ Ways of Coping Questionnaire } \\
\hline $\begin{array}{l}\text { Ways of Coping - } \\
\text { Confront problem }\end{array}$ & $5.94(3.47)$ & $2.25(1.83)$ \\
\hline $\begin{array}{l}\text { Ways of Coping - } \\
\text { Distancing }\end{array}$ & $6.81(3.89)$ & $4.88(3.56)$ \\
\hline $\begin{array}{l}\text { Ways of Coping - } \\
\text { Self control }\end{array}$ & $11.13(3.54)$ & $10.50(4.28)$ \\
\hline $\begin{array}{l}\text { Ways of Coping - } \\
\text { Social support }\end{array}$ & $8.75(3.55)$ & $7.71(4.42)$ \\
\hline $\begin{array}{l}\text { Ways of Coping - } \\
\text { Accept responsibility }\end{array}$ & $5.29(2.42)$ & $3.13(1.89)$ \\
\hline $\begin{array}{l}\text { Ways of Coping - } \\
\text { Escape avoidance }\end{array}$ & $7.19(3.51)$ & $5.00(4.41)$ \\
\hline $\begin{array}{l}\text { Ways of Coping - } \\
\text { Planful problem solving }\end{array}$ & $8.88(3.35)$ & $9.38(4.34)$ \\
\hline $\begin{array}{l}\text { Ways of Coping - } \\
\text { Positive reappraisal }\end{array}$ & $6.06(4.99)$ & $2.75(2.12)$ \\
\hline $\begin{array}{l}\text { Cooper et al. Index of } \\
\text { Dental-Related Stress }\end{array}$ & 99.94 (22.92) & $90.67(19.22)$ \\
\hline
\end{tabular}

participant to specialist sources of assistance (financial, educational, clinical support, management and personnel issues) or identify specific counselling related needs. The interventions provided by the service are designed to be problem focussed and time limited. As part of the evaluation of this service, a prospective cohort study of 20 general dental practitioners was conducted. Assessments were made of the levels of stress experienced by the participants, their psychological distress and their ways of coping with stress, before and six months after their attendance at a service designed to assist with their experience of stress. In addition at the post-attendance evaluation participants were asked to complete a standardised scale evaluating their experience of the treatment.

The dental practitioners completed the following measures immediately before their first consultation with the DPSS:

The sources and level of stress dentists experience in their work life (The Work Stress Inventory ${ }^{4}$ ). This scale comprises a number of sources of stress and respondents are asked to indicate which source of stress they have experienced in their work life recently. Higher scores on this scale indicate higher amounts of stress.
Table 3 Comparison of measures at pre-and post-intervention

\begin{tabular}{|c|c|c|}
\hline Measure & Z statistic & Significance \\
\hline $\begin{array}{l}\text { General Health } \\
\text { Questionnaire } \\
\text { (General distress) }\end{array}$ & -2.18 & $P=0.03$ \\
\hline \multicolumn{3}{|l|}{$\begin{array}{l}\text { Clinical Outcomes in } \\
\text { Research \& Evaluation }\end{array}$} \\
\hline CORE - F & -0.67 & $P=0.50 \mathrm{~ns}$ \\
\hline CORE - P & -1.86 & $P=0.06 n s$ \\
\hline CORE - W & -1.22 & $P=0.22 n s$ \\
\hline CORE - R & -1.07 & $P=0.29 n s$ \\
\hline CORE - TOTAL & -0.85 & $P=0.40 \mathrm{~ns}$ \\
\hline \multicolumn{3}{|l|}{$\begin{array}{l}\text { Ways of Coping } \\
\text { Questionnaire }\end{array}$} \\
\hline $\begin{array}{l}\text { Ways of Coping - } \\
\text { Confront problem }\end{array}$ & -2.03 & $P=0.04$ \\
\hline $\begin{array}{l}\text { Ways of Coping - } \\
\text { Distancing }\end{array}$ & -1.70 & $P=0.09 n s$ \\
\hline $\begin{array}{l}\text { Ways of Coping - } \\
\text { Self control }\end{array}$ & -1.02 & $P=0.31 \mathrm{~ns}$ \\
\hline $\begin{array}{l}\text { Ways of Coping - } \\
\text { Social support }\end{array}$ & -0.84 & $P=0.40 \mathrm{~ns}$ \\
\hline $\begin{array}{l}\text { Ways of Coping - } \\
\text { Accept responsibility }\end{array}$ & -2.39 & $P=0.02$ \\
\hline \multicolumn{3}{|l|}{$\begin{array}{l}\text { Ways of Coping - } \\
\text { Escape avoidance }\end{array}$} \\
\hline $\begin{array}{l}\text { Ways of Coping - } \\
\text { Planful problem solving }\end{array}$ & 0.85 & $P=0.40 \mathrm{~ns}$ \\
\hline $\begin{array}{l}\text { Ways of Coping - } \\
\text { Positive reappraisal }\end{array}$ & -0.32 & $P=0.75 \mathrm{~ns}$ \\
\hline $\begin{array}{l}\text { Cooper et al. Index of } \\
\text { Dental-Related Stress }\end{array}$ & -1.24 & $P=0.21 \mathrm{~ns}$ \\
\hline
\end{tabular}

Coping style (McCarthy Ways of Coping Questionnaire ${ }^{25}$ ). This scale identifies a number of techniques of coping with stress, including positive coping techniques and avoidance based techniques (see Table 2 for details of the coping styles). Higher scores on all scales indicate greater use of that coping style.

Psychological distress (Clinical Outcomes in Evaluative Research; ${ }^{26}$ General Health Questionnaire ${ }^{27}$ ). For both scales higher scores indicate greater psychological distress.

The support offered to the practitioners was consistent with the philosophy of the service and comprised a time limited consultation (maximum of six hours) with the consultants in the DPSS. Interventions were tailored to meet the individual needs of general dental practitioners within the framework of the six hours. Notes were made by the consultants in the service of the problem areas addressed in the sessions and the methods used to address these concerns. A summary of the range and type of issues covered by the consultants is given in Table 1 . The techniques adopted by the consultants were various including counselling and therapeutic approaches, teaching and role play, and the identification of information and resources. 
Table 4 Analysis of respondents' views of treatment using the Treatment Evaluation Inventory

\begin{tabular}{llll}
\hline Scale & $\begin{array}{l}\text { Theoretical range } \\
\text { Minimum }\end{array}$ & Maximum & $\begin{array}{l}\text { Rating by participants } \\
\text { Mean (SD) }\end{array}$ \\
\hline Total score & 19 & 95 & $73.9(11.75)$ \\
Progress & 11 & 55 & $38.08(8.72)$ \\
Acceptability & 8 & 40 & $35.85(4.56)$
\end{tabular}

One month after the dentists completed their treatment, they were asked to complete the questionnaires as given in the pre-intervention assessment. In addition, participants were asked to complete questionnaires measuring their view of the intervention they received (Treatment Evaluation Inventory ${ }^{28}$ ).

Although 20 dental practitioners were recruited to the study, one failed to provide complete data at the initial consultation and therefore could not be included in the analysis and a further three participants failed to attend any of the sessions organised for them by the service (no information on these drop outs was obtained). The 16 participants who commenced treatment were followed up at the completion of the sessions at which time returns were received from nine participants (45\%).

Table 2 identifies the mean scores of the participants on all measures at Time 1 and Time 2. In general all measures show reductions between the two testing occasions. Given the small sample sizes on the two testing occasions, and the likelihood that the data come from non-normal distributions, non-parametric analyses were used to compare the participants on the two occasions of testing. Specifically the Wilcoxon Signed Ranks Test was used. The comparison of all scales at Time 1 and Time 2 is summarised in Table 3. Significant reductions in the experience of distress as measured by the General Health Questionnaire and changes in the use of specific ways of coping with stress, that is confronting the problem and accepting responsibility for the stress, were noted. Those participants that completed the intervention were both less likely to confront their problems and to accept responsibility, perhaps suggesting that they were accepting that the sources of their stress were outside their control. Such coping mechanisms are perhaps appropriate to some of the situations described by the participants as being the source of their stress.

Table 4 shows the ratings of the treatment made by participants using the Treatment Evaluation Inventory. These findings suggest that the participants find the service acceptable and rate themselves as showing good progress in dealing with their stress.

This small scale study provides some evidence that intervention programmes tailored to the specific needs of general dental practitioners can significantly reduce their experience of distress and modify their habitual coping mechanisms. The intervention described here was not standardised to a great degree but allowed trained consultants to work with the dentists to a maximum of six one hour sessions. However this study has a number of limitations which restrict the conclusions that can be drawn. In considering the limitations of the study it is important to explore the pattern of loss of participants. An initial loss of information occurred when participants recruited to the scheme failed to attend the service. It is not clear why individuals chose not to attend and this may occur for both positive and negative reasons. On the positive side it may be that there was spontaneous remission of stress related difficulties, on the negative side the prospective participants may have viewed the service as not relevant or useful to their needs. The response rate to the questionnaires at the end of the study was disappointing. This arose in part because the questionnaires were posted to participants some time after they had left the service at which time they would have returned to their stressful environments with many demands on their time. It is therefore possible that those participants who responded at follow up were experiencing less stress than the non-responders which would suggest the intervention was less effective than the results would suggest. The sample size is small though in part the power of the study is enhanced by the within-groups design. Limitations of funding for evaluation meant that a larger sample could not be collected. The absence of a no-treatment control group limits the conclusions that can be drawn since there may be spontaneous remission of stress.

The exact nature of the intervention could not be specified since individual counsellors worked with dentists to address the issues most pertinent. As a result these data cannot be taken as an evaluation of any specific intervention, but rather the endorsement of an approach to intervening with stressed dental practitioners through the provision of structured counselling sessions. Such a service is valued by the dental practitioners who experienced it.
CONCLUSIONS AND FUTURE DIRECTIONS

Given that the experience of stress and burn-out among dental practitioners is both prevalent and potentially harmful, there is a need for the development and evaluation of interventions to reduce the stress experienced by members of the dental team. In addressing this need, a number of issues arise. Interventions may be either highly structured, comprising similar interventions for all participants regardless of the nature and level of their stress, or unstructured and tailored to individual needs. The former will provide a much clearer basis for systematic evaluation and allow the researcher to identify those components of an intervention which are most effective. They also allow for greater comparability across research and practice settings. Unstructured interventions have greater face validity and may be more acceptable to the staff undertaking interventions. An approach which seeks to balance structured and unstructured interventions such as that described here may obtain the advantages of both.

The design of evaluation should include appropriate control groups and be of sufficient size to gain statistical validity. Evaluations should also include long term follow ups to determine the sustainability of change, especially given evidence that change may be short lived. ${ }^{24}$

Finally there has been no published research investigating the efficacy of primary prevention in the management of stress amongst the dental team. This is an area which may prove fruitful, and could include training in stress management for members of the dental team during their training.

1. Gibbons D E, Newton J T. Stress solutions for the overstretched. London: Macmillan, 1998.

2. Matthews K A, Gump B B. Chronic work stress and marital dissolution increase risk of posttrial mortality in men from the Multiple Risk Factor Intervention Trial. Archives Internal Med 2002: 162: 309-315.

3. Freeman $R$, Main JR R, Burke FJ T. Occupational stress and dentistry: Theory and practice. Part I Recognition. Br Dent J 1995; 178: 214-217.

4. Cooper C L, Watts J, Kelly M. Job satisfaction, mental health and job stressors among general dental practitioners in the UK. Br Dent J 1987; 162: 77-81.

5. Wilson R F, Coward PY, Capewell I etal. Perceived sources of occupational stress in general dental practitioners. Br Dent J 1998; 184: 499-502.

6. Newton J T, Gibbons D E. Stress in dental practice: A qualitative comparison of dentists working within the NHS and those working within an independent capitation scheme. Br Dent J 1996; 180: 329-334.

7. Gorter R C, Eijkman M A. Career expectations and the type of dentist in the light of burnout. Nederlands Tijdschrift voor Tandheelkunde 2002; 109: 212-216.

8. Newton T, Mistry, K, Patel A etal.Stress in denta specialists: A comparison of six clinical dental specialities. Primary Dent Care 2002; 9: 100-104.

9. Hockemeyer J, Smyth J. Evaluating the feasibility and efficacy of a self-administered manual-based stress management intervention for individuals with asthma: Results from a controlled study. Behavioral Medicine 2002; 27: 161-172.

10. Batey D M, Kaufman P G, Raczynski J M et al. 
Stress management intervention for primary prevention of hypertension: Detailed results from Phase I of Trials of Hypertension Prevention (TOHP-I). Annals of Epidemiology 2000; 10: 45-58.

11. Persson $L G$, Lindstrom $K$, Lingfors $H$, Bengtsson $C$. Results from an intervention programme dealing with cardiovascular risk factors: Experiences from a study of men aged 33-42 in Habo, Sweden.

Scandinavian J Primary Health Care; 1996; 14: $184-$ 192.

12. Kreutzer J S, Kolakowsky-Hayner S A, Demm SR, Meade M A. A structured approach to family intervention after brain injury. J Head Trauma Rehabilit 2002; 17:349-367.

13. Mizuno E, Hosak T, Ogihara R et al. Effectiveness of a stress management program for family caregivers of the elderly at home. J Med Dent Sci 1999; 46: 145153.

14. Schulz R, O'Brien A, Czaja S et al. Dementia caregiver intervention research: In search of clinical significance. Gerontologist 2002; 42: 589-602.

15. Briner R B. Improving stress assessment: Toward an evidence-based approach to organisational stress interventions. J Psychosomatic Res 1997: 43: 61-71.

16. Cooper C L, Cartwright S. An intervention strategy for workplace stress. J Psychosomatic Res 1997; 43: 7-16.

17. Isreal B A, Baker EA, Goldenhar L M et al. Occupational stress, safety and health: Conceptual framework and principles for effective prevention interventions. J Occupational Health Psych 1996; 1 : 261-286.

18. Carlier IV, Voerman A E, Gersons B P. The influence of occupational debriefing on post-traumatic stress symptomatology in traumatized police officers. $\mathrm{Br} J$ Med Psych 2000; 73: 87-98

19. Deahl M, Srinivasan M, Jones Net al. Preventing psychological trauma in soldiers: The role of occupational stress training and psychological debriefing. Br J Med Psych 2000; 73: 77-85.

20. Rydstedt L W, Johansson G, Evans GW. The human side of the road: Improving the working conditions of urban bus drivers. J Occupational Health Psych 1998; 3: 161-171.

21. Humphris G M. Improved working conditions and professional support will benefit young dentists. $\mathrm{Br}$ Dent J 1999; 186: 28

22. Reynolds S. Psychological well-being at work: Is prevention better than cure? J Psychosomatic Res 1997; 43: 93-102.

23. Gorter R, Hoogstraten J, Eijkman M. A career counselling program for dentists: Effects on burnout Patient Education \& Counselling 2001; 43: 23-30.

24. Brake $H \mathrm{~T}$, Gorter R, Hoogstraten J, Eijkman M. Burnout intervention among Dutch dentists: long term effects. Europ J Oral Sci 2001; 109: 380-387.

25. McCarthy A H. Ways of coping questionnaire handbook. San Diego: Consulting Psychologists Press Ltd, 1988.

26. CORE Systems Group. Core Systems (Information management) Handbook. Leeds: Core systems group, 1998.

27. Goldberg D H. General Health Questionnaire-12. Windsor: NFER Nelson, 1992.

28. Newton JT, Sturmey P. Development of a short form of the Treatment Evaluation Inventory for the acceptability of psychological interventions. Psych Reports 2004; 94: 475-481.

\section{BDJ Correction}

\section{Vol 200 No. 5, Mar 11 2006, p272}

\section{Smoking cessation advice for patients with chronic periodontitis}

In this research article the author biography section was published in an incomplete format - the author roles were omitted. The authors were:

H. A. Nasry, ${ }^{1}$ P. M. Preshaw, ${ }^{2}$ F. Stacey, ${ }^{3}$ L. Heasman, ${ }_{1}^{4}$ M. Swan ${ }^{5}$ and P. A. Heasman ${ }^{6}$

Their roles are: ${ }^{1}$ Specialist Registrar in Restorative Dentistry, Newcastle Dental Hospital; ${ }^{2}$ Senior Lecturer, School of Dental Sciences, University of Newcastle Upon Tyne; ${ }^{3}$ Research Hygienist, School of Dental Sciences, University of Newcastle Upon Tyne; ${ }^{4}$ Research Hygienist, School of Dental Sciences, University of Newcastle Upon Tyne; ${ }^{5}$ Research Hygienist, School of Dental Sciences, University of Newcastle Upon Tyne; ${ }^{6}$ Consultant in Restorative Dentistry, School of Dental Sciences, University of Newcastle Upon Tyne.

We apologise for this error and are grateful to the authors for pointing it out. 